\title{
A new solution for destruction of PCDD/Fs by a catalytic filter system at waste incinerators
}

\author{
Zhengtian $\mathrm{Xu}^{1}$, Hong Sun ${ }^{2, *}$, Xueqing $\mathrm{Li}^{3}$, and Eiji Motoda ${ }^{4}$ \\ ${ }^{1}$ W.L. Gore \& Associates, Inc., 101 Lewisville Road, Elkton, MD 21921, USA \\ ${ }^{2}$ Gore Industrial Products (Shanghai) Co., Ltd., Floor 43, United Plaza, 1468 Nanjing Road West, Shanghai, 200040, China \\ ${ }^{3}$ Huaqiao University (Environmental Engineering),668 Jimei Avenue, Jimei District, Xiamen, Fujian, 361021, China \\ ${ }^{4}$ W.L. Gore \& Associates, Co., Ltd. 1102-4 Mitsukouchi, Kita-ku, Okayama-Shi,Okayama,709-2123, Japan
}

\begin{abstract}
Polychlorinated dibenzo-p-dioxins and dibenzofurans (PCDD/Fs) are emitted from high temperature combustion processes such as municipal waste incinerators, hazardous waste incinerators, medical waste incinerators, and secondary metal processing plants. Due to their extreme toxicity, stringent regulations on PCDD/Fs emissions have been in effect around the world since the early 1990s. W. L. Gore \& Associates, Inc. developed a catalytic filter system in 1997 that can effectively remove and destroy $\mathrm{PCDD} / \mathrm{Fs}$ in the industrial flue gases. The REMEDIATM Catalytic Filter System has been installed in various industrial facilities around the world. The dioxin emission measurements in these plants achieve more than $98 \%$ PCDD/Fs removal efficiencies and reach the European standard. In this paper, three case studies will be presented on the performance of the REMEDIA Catalytic Filter System at municipal, medical, and hazardous waste incinerators. Three cases in the paper demonstrate the efficiency and results.
\end{abstract}

\section{Introduction}

There are three sources of PCDD/Fs from incineration processes. The first source of $\mathrm{PCDD} / \mathrm{Fs}$ occurs as trace constituents in the waste itself, and a portion survives the incineration process and is carried through in the flue gas. The amount of PCDD/Fs from this source is relatively small compared to the other sources. The second source for $\mathrm{PCDD} / \mathrm{Fs}$ formation is through pyrolysis processes from precursors in the wastes such as PCBs, chlorinated phenols, chlorinated benzenes, etc. The third source of $\mathrm{PCDD} / \mathrm{Fs}$ is through "de novo Synthesis" from materials not directly related to these compounds, the result of heterogeneous catalytic reaction on fly ashes, during the gas cooling process. A common solution to remove $\mathrm{PCDD} / \mathrm{F}$ from the flue gas is injection of powder activated carbon into the flue gas upstream of the baghouse. Activated carbon can adsorb PCDD/Fs in the gas phase and remove them by fabric filter bags in a baghouse. However, carbon injection also creates problems, the plant needs to purchase additional equipment, obtains adequate storage, and disposes the large quantity of contaminated ashes.

The REMEDIA ${ }^{\mathrm{TM}}$ Catalytic Filter System developed by W. L. Gore and Associates, Inc. is an evolution of two proven technologies: catalysis and surface filtration.

The filter is a needle punched felt made from ePTFE fibers containing a proven dioxin-destroying catalyst. The catalytic felt destroys gaseous PCDD/F at low temperatures $\left(180^{\circ} \mathrm{C}-260^{\circ} \mathrm{C}\right)$ by means of a catalytic reaction. $\mathrm{PCDD} / \mathrm{F}$ molecules diffuse on the catalyst surface and react to form insignificant amounts of $\mathrm{CO}_{2}$, $\mathrm{H}_{2} \mathrm{O}$, and $\mathrm{HCl}$. The pictures in Figure 1 show the REMEDIA Catalytic Filters and the details of the catalytic fibers.

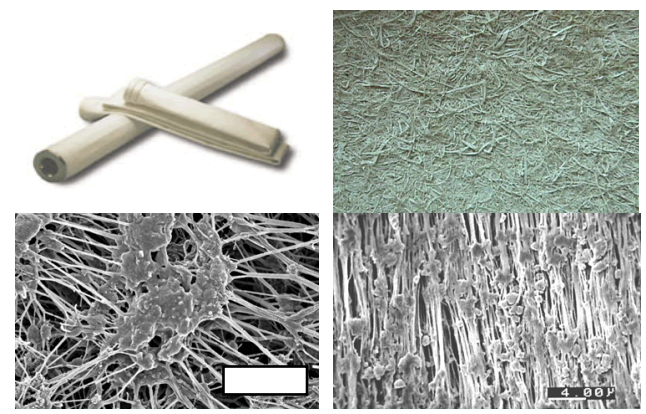

Fig. 1. REMEDIA ${ }^{\mathrm{TM}}$ Catalytic Filters and SEM Pictures of Catalytic Fiber

The filters also employ a microporous, ePTFE membrane for particulate control, which is laminated to the catalytic felt substrate. The membrane, which is a GORE ${ }^{\circledR}$ membrane, captures submicron particulate without allowing particles to penetrate or pass through the catalytic felt substrate. Thus, the membrane provides a means for capturing particulate containing adsorbed PCDD/Fs (i.e., solid-phase PCDD/Fs). Gaseous $\mathrm{PCDD} / \mathrm{Fs}$, however, pass through the membrane and into the catalytic felt. The catalysis and surface filtration principles are illustrated in Figure 2.

\footnotetext{
* Corresponding author: hsun@wlgore.com
} 


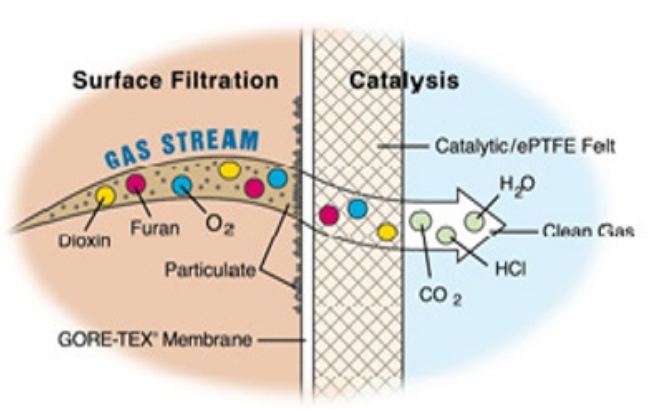

Fig. 2. Cross-sectional view of the catalytic filter. The membrane emoves particulate while the catalytic felt destroys gaseous $\mathrm{PCDD} / \mathrm{Fs}$

This paper demonstrates the performance of the REMEDIA $^{\mathrm{TM}}$ Catalytic Filter System at a medical waste incinerator, a municipal waste incinerator, and a hazardous waste incinerator. The case studies are from plants in the US, Belgium, and China.

\section{Methods and materials}

\subsection{Captions/numbering}

All raw gas and stack measurements for the US plant were conducted according to US EPA method 23. The sampling and analysis procedures for the European plant followed the European standard method EN 1948i, which is binding upon Europe. The measurements at the Japanese plant were performed according to the JIS K 0311-method ${ }^{\text {ii }}$. Both methods differ only in some details from the US EPA method 23 and lead to comparable results ${ }^{\mathrm{i}}$. Details are described in the methods.

\section{Results and analysis}

\subsection{REMEDIA ${ }^{\text {TM }}$ Catalytic Filter System in a Medical Waste Incinerator}

The Baltimore Regional Medical Waste Incinerator in the US processes regulated medical waste and general waste from hospitals and clinics in Baltimore, Maryland, and from healthcare institutions throughout the midAtlantic area of the United States. The plant, which began commercial operation in January of 1991, is the largest dedicated medical waste incinerator in the world.

The process consists of two identical controlled airtype incineration lines, each with a nominal-processing rate of 77 metric tons of waste per day. Each incineration line comprises primary, secondary, and tertiary combustion chambers, a heat recovery steam generator, and a dry-injection/fabric filter air pollution control system.

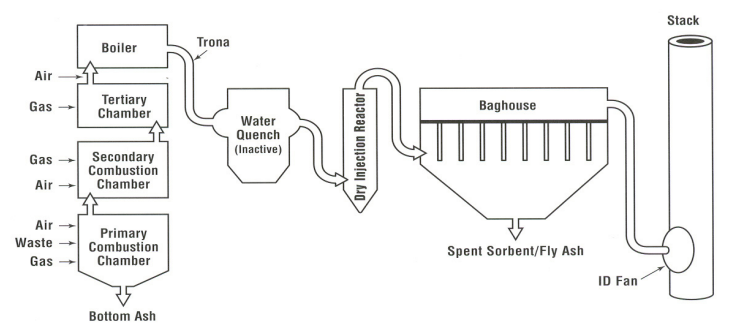

Fig. 3. Plant Configuration for Baltimore Regional Medical Waste Incinerator Facility

The plant performed PCDD/Fs stack measurement in late 1995, with both standard powdered activated carbon (PAC) and a proprietary activated carbon product, injected into the flue gas. The results were acceptable for both materials. However, the plant was not satisfied due to higher disposal cost of contaminated fly ash and concern over possible fires in the baghouse from carbon sparks.

In late 1997, W. L. Gore and Associates, Inc. introduced REMEDIA Catalytic Filter System to the plant. Compared to conventional PAC injection, the new technology offered the following advantages to the medical waste incinerator:

- Gas phase PCDD/Fs are destroyed, rather than simply being adsorbed on a solid.

- The system is a passive solution, without the need for a new chemical feed system.

- Conversion to the new technology is simply a matter of rebagging the baghouses.

- Potential future liabilities associated with $\mathrm{PCDD} /$ Fs contaminated solid residues are reduced.

- The system provides the particulate capture, filter pressure drop, and mechanical life advantages of an ePTFE filter media.

Beginning in May 1999, both baghouses were completely refitted with the REMEDIA ${ }^{\mathrm{TM}}$ Catalytic Filter System, to simultaneously control PCDD/Fs and particulate matter. In January 2000, PCDD/Fs measurements were performed to evaluate the performance of the catalytic filters in baghouse \#2.

Figure 4 presents total PCDD/F concentrations (solid + gas phase) in the raw gas and clean gas. The data are presented as I-TEQ values. The PCDD/Fs removal efficiency is $98.4 \%$ on a TEQ basis.

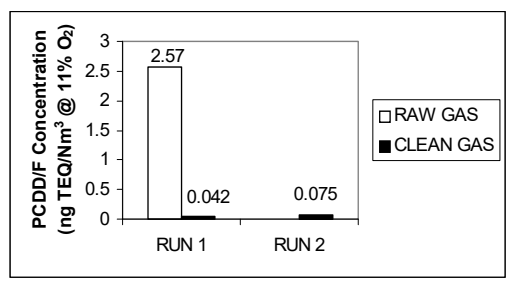

Fig. 4. Total PCDD/F Concentrations in the Raw and Clean Gas. 
Figure 5 presents the total particulate matter (PM) concentrations in the raw gas and clean gas. Over the two runs, the average PM removal efficiency is $99.95 \%$. The PM concentrations in the clean gas are 12-17 times lower than the emission guideline of $34 \mathrm{mg} / \mathrm{dscm} @ 7 \%$ $\mathrm{O}_{2}\left(26 \mathrm{mg} / \mathrm{Nm}^{3} @ 11 \% \mathrm{O}_{2}\right)$.

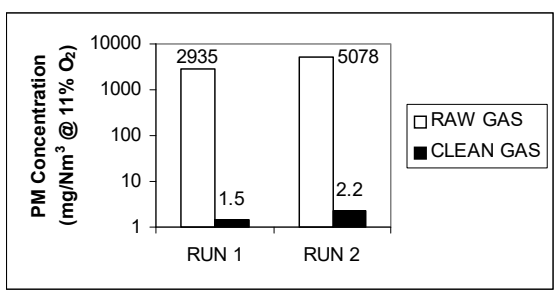

Fig. 5. PM Concentrations in the Raw and Clean Gas.

The key findings of the $\mathrm{PCDD} / \mathrm{Fs}$ and $\mathrm{PM}$ measurement campaign are:

- The total PCDD/F removal efficiency is $98.4 \%$.The

- $\quad$ amount of gas phase PCDD/Fs destroyed by the catalytic filters is 1.73 ng TEQ/Nm3 @ 11\% O2 or $97.7 \%$.

- $\quad 99.9 \%$ of solid phase $\mathrm{PCDD} / \mathrm{Fs}$ is removed by the catalytic filters.

- The clean gas PCDD/F concentrations are $<0.1$ ng TEQ/Nm3 @ 11\% O2 and are more than one order of magnitude lower than the emission guideline and historical values.

- The PM removal efficiency is $99.95 \%$ and clean gas PM concentrations are 12-17 times lower than the emission guideline.

\subsection{REMEDIA ${ }^{\mathrm{Tm}}$ Catalytic Filter System in a Municipal Waste Incinerator}

The IVRO municipal waste incinerator is located in Roeselare, Belgium. The plant configuration is shown in Figure 6. The plant was built in 1976 and consists of two incinerator lines, each having its own air pollution control train consisting of an electrostatic precipitator, dry lime scrubber, and fabric filter. Each incinerator and flue gas cleaning line feed into one common stack. Over the years the capacity of each incinerator line has increased from 3.2 tons of waste per hour to 4 tons of waste per hour. In 1996, new PCDD/Fs regulations were enacted, prompting IVRO to install a powdered activated carbon (PAC) injection system. The PAC system was used at temperatures of $200^{\circ} \mathrm{C}-230^{\circ} \mathrm{C}$. At these high temperatures corrosion can be kept to a minimum, however, there is an increased risk of a fire in the fabric filter. Also the absorption of the carbon is reduced.To avoid the risk of fires and plant shutdowns, IVRO began to look for alternatives to PAC. In 1998 IVRO equipped both incinerator lines with REMEDIA catalytic filters. The replacement of existing bags are very simple. The new Remedia bags are with same size as previous bags on site.The replacement is quick.It is no any changing about the bag house and flue gas cleaning system on the plant.

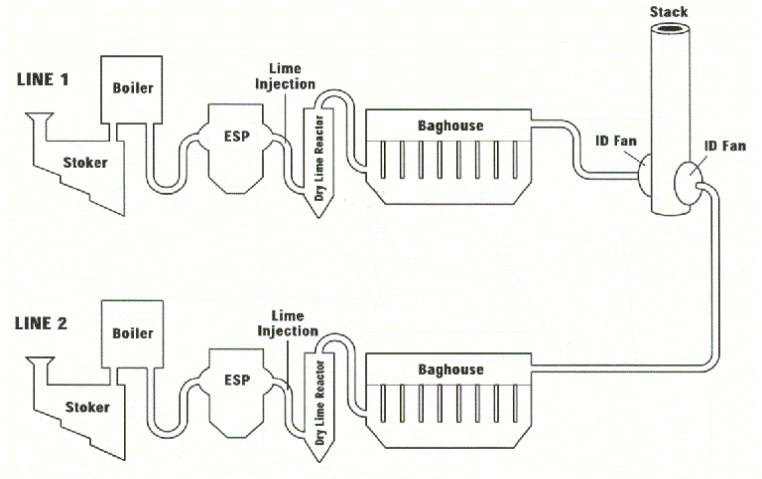

Fig. 6. Plant configuration for the IVRO Municipal Waste Incinerator.

In the Flanders region of Belgium where IVRO is located, municipal waste incinerators are not allowed to operate unless the $\mathrm{PCDD} / \mathrm{Fs}$ regulatory limit of $0.1 \mathrm{ng} \mathrm{I}-$ $\mathrm{TEQ} / \mathrm{Nm}^{3}$ is met. Continuous sampling and bi-weekly analysis for $\mathrm{PCDD} / \mathrm{Fs}$ are performed to ensure compliance with the regulation during all stages of operation, including startup and shutdown.

Figure 7 shows PCDD/Fs inlet ("raw gas") concentrations and outlet ("clean gas") emissions at IVRO since installation of the catalytic filters. Emissions have been well below the $0.1 \mathrm{ng}$ I-TEQ/ $/ \mathrm{Nm}^{3}$ regulatory limit over a period of 72 months.

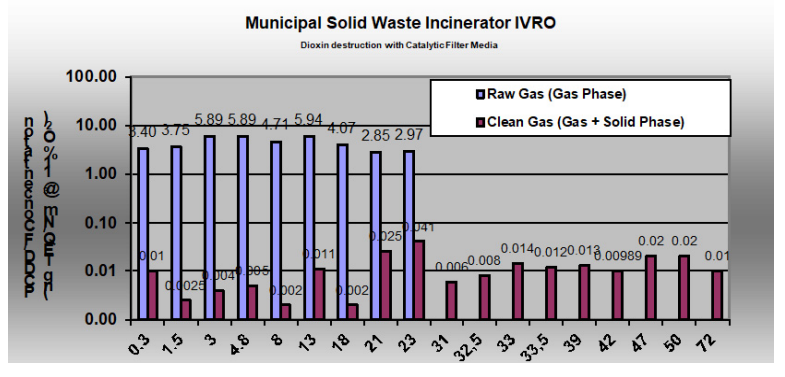

Fig. 7. Plant configuration for the IVRO Municipal Waste Incinerator.

Figure 8 shows the distribution of all toxic isomers in the raw and clean gas for this same measurement on Line 1. The reduction of gas-phase $\mathrm{PCDD} / \mathrm{F}$ is greater than $99.29 \%$ for all toxic isomers.

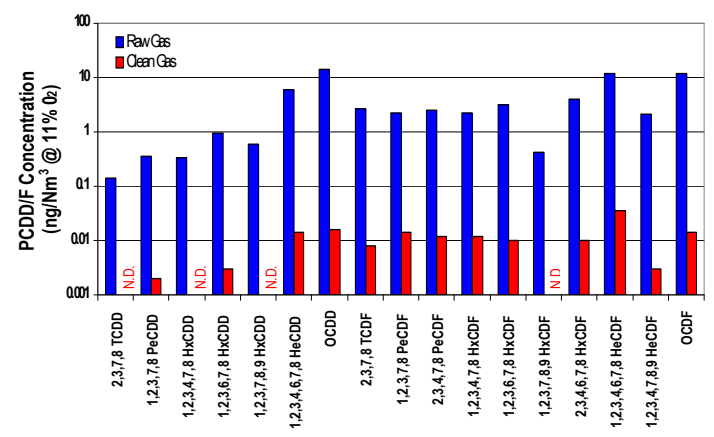

Fig. 8. PCDD/Fs concentrations in the raw and clean gas for all toxic isomers - non-TEQ basis. 
The performance of a catalytic filter system at the IVRO municipal waste incinerator has been monitored for over 72 months. Over this time, IVRO has maintained $\mathrm{PCDD} / \mathrm{F}$ emissions well below the regulatory limit of $0.1 \mathrm{ng} \mathrm{I}-\mathrm{TEQ} / \mathrm{Nm}^{3}$. The system reduces the raw gas concentration of each toxic isomer by more than $99 \%$. Particulate removal was measured at more than 99.98\%. By performing a mass balance for PCDD/Fs going in and out of the fabric filter, it was demonstrated that greater than $99.5 \%$ of the incoming $\mathrm{PCDD} / \mathrm{Fs}$ is destroyed by the catalyst. As a result of adopting the catalytic filter technology, IVRO has been able to maintain temperatures in the fabric filter, which inhibit corrosion, and has ceased using PAC, thus avoiding the risk of fire and plant shutdowns.

\subsection{REMEDIA ${ }^{\mathrm{TM}}$ Catalytic Filter System in a Hazardous Waste Incinerator in China}

Shanghai HWI uses the rotary kiln for waste pretreatment and combustion. A gas-cooling tower cools down the flue gas emitted from the furnace. A mixture of powder activated carbon and lime is injected upstream of the baghouse. The baghouse temperature is maintained between 190 and $200^{\circ} \mathrm{C}$. There are three lines in this plant and operates continuously daily with waste capacity of 134 ton/day. The flue gas flow rate for line $3 \#$ is $13,000 \mathrm{Nm}^{3} / \mathrm{h}$. Figure 9 shows the process flow chart.

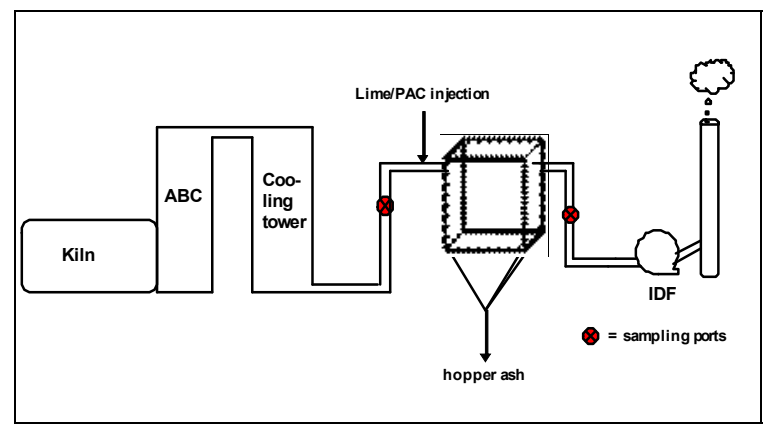

Fig. 9. $\mathrm{PCDD} /$ Fs concentrations in the raw and clean gas for all toxic isomers - non-TEQ basis.

It is one of the local HWIs in Shanghai. The location is very closer to town of Shanghai. In China, the $\mathrm{PCDD} / \mathrm{Fs}$ emission limit of $0.5 \mathrm{ng} \mathrm{TEQ} / \mathrm{Nm}^{3}$ for $\mathrm{HWI}$ was established in 2001 as GB281484-2001. But Shanghai local government required tighter emission limit of $0.1 \mathrm{ng} \mathrm{TEQ} / \mathrm{Nm} 3$ earlier. Before the REMEDIA $^{\text {TM }}$ Catalytic Filter System was installed at this HWI plant, the PCDD/Fs emissions were higher than 0.1 ng TEQ $/ \mathrm{Nm}^{3}$ with mixture of activated carbon and lime injection sometimes. A proposal of using a catalyst tower was rejected because of the need for additional equipment and the bigger food space. In year 2013, the plant decided to use the REMEDIA Catalytic Filter System to control the dioxin emission at the hazardous waste incinerator. The installation of the REMEDIA Catalytic Filter System at Shanghai HWI line3\# was completed in March 2014 and the rest two lines was completely in October 2014.

The measurement of $\mathrm{PCDD} / \mathrm{Fs}$ at the HWI was performed in April of 2014, after one month of operation for line $2 \#$ and line $3 \#$.

Before the installation of the REMEDIA ${ }^{\mathrm{TM}}$ Catalytic Filter System, the stack concentration of $\mathrm{PCDD} / \mathrm{F}$ was higher than $0.1 \mathrm{ng}$ TEQ-WHO/ $\mathrm{Nm}^{3}$. The REMEDIA Catalytic Filter System effectively reduced the PCDD/Fs concentration from the inlet of $11.6 \mathrm{ng}$ TEQ-WHO/ $\mathrm{Nm}^{3}$ to $0.015-0.018 \mathrm{ng}$ TEQ-WHO/ $\mathrm{Nm}^{3}$ at the outlet of line $1 \# \&$ 2\# tested dated April, 2014 and 0.02-0.03 ng TEQ$\mathrm{WHO} / \mathrm{Nm}^{3}$ of line $3 \#$ tested dated December 2014 . The removal efficiency is above $99.6 \%$.

\section{Conclusion}

The dioxin measurements results at Baltimore Regional Medical Waste Incinerator (US), IVRO Municipal Waste Incinerator (Belgium), and Shanghai Hazardous Waste Incinerator (China) show that the REMEDIA Catalytic Filter System has achieved the effective removal of PCDD/Fs from the flue gases. This technology can be applied to variety of industrial incineration processes for $\mathrm{PCDD} / \mathrm{Fs}$ reduction. The PCDD/Fs in the flue gases are destroyed, without requiring further treatment of PCDD/Fs contaminated fly ashes. Applying this technology for dioxin emission control also reduces the risk of downstream contaminations.

\section{References}

1. EN 1948: Stationary source emissions, determination of the mass concentration of PCDD/PCDFs, Part 1: sampling; Part 2: extraction and clean-up; Part 3: identification and quantification; CEN- European Committee for Standardization, 1996

2. JIS K 0311: Method for determination of tetrathrough octa-chlorodibenzo-p-dioxins, tetra- through octa-chlorodibenzofurans and coplanar polychlorobiphenyls in stationary source emissions, 1999

3. a. Wallbaum U., Lamparski L., Nestrick T., Krueger J., Wilken M.: Comparison of Dioxin sampling methods; USA EPA method 23 versus two German VDI methods. Organohalogen Compounds 23, (1995), 53-57

4. H. Huang, A. Buekens. De novo Synthesis of Polychlorinated Dibenzo-p-dioxins and dibenzofurans Proposal of a mechanistic Scheme. The Science of the Total Environment, 1996, 193: 121-141

5. Guideline for Controlling PCDDs/DFs in MSW Management, the Advisory Committee for Controlling PCDDs/PCDFs in MSW Management, 1997.

6. M. Plinke, R. Sassa, W. Mortimer, G. Brinckman. Catalytic Filter Material and Method of Making 
Same. US Patent No. 5,620,669 (1997) to W.L.

Gore \& Associates

7. J. L. Bonte, M. Plinke, R. Dandarow, G. Brinckman, M. Waters, K. Overberghe, H. Heuvel. Catalytic Filtration: Dioxin/Furan Destruction in the Baghouse. Organohalogen Compounds, 1999, 40, 459-464

8. S. Kreisz, H. Hunsinger, H. Vogg. Wet Scrubbers A Potential PCDD/F Source? Chemosphere, 1996, 32(1): $73-78$ 